\title{
Treatment of chronic HCV infection in people co-infected with HIV in a Spanish tertiary hospital and in relation to real life
}

\author{
Ferra Murcia $\mathrm{S}^{1 *}$, Parrón Carreño T $\mathrm{T}^{2,3}$, Díez García LF ${ }^{1}$ and Collado Romacho $\mathrm{A}^{1 *}$ \\ ${ }^{1}$ Infectious Diseases Unit, Torrecárdenas University Hospital, Almería, Andalusia, Spain \\ ${ }^{2}$ School of Health Sciences, University of Almeria, Almeria, Spain \\ ${ }^{3}$ Territorial Delegation of Equality, Health and Social Policies, Health Delegation of Almeria, Junta de Andalucía, Almeria, Spain
}

\begin{abstract}
Background: Nowadays the consequences of hepatitis C virus (HCV) in patients co-infected with Human Virus Immunodeficiency (HIV) are significant and include accelerated progression of liver disease, high rates of end-stage liver disease and a less survival after liver decompensation. Thanks to direct-acting antiviral drugs (DAA) in non-interferon regimens, cure rates above $95 \%$ have been achieved with fewer side effects, allowing for effective short treatments. In real life, transitional elastography allows for effective and close monitoring without the need for invasive procedures such as liver biopsy.
\end{abstract}

Objectives: To analyse the characteristics of $\mathrm{HIV} / \mathrm{HCV}$ co-infected patients treated with DAAs in Interferon-free regimens in relation to real life in a Spanish tertiary Hospital.

Methods: Retrospective descriptive study. Review of the clinical history of the first 100 treatments with DAAs interferon-free in HIV/HCV co-infected patients treated in our centre.

Results: A total of 100 different treatments corresponding to $98 \mathrm{HIV} / \mathrm{HCV}$ co-infected patients on follow-up were included in the analysis. Seventy-three (73\%) were male. Forty-six (46.9\%) had been previously treated with pegylated interferon and ribavirin (PR), of which only $11 \%$ had had a partial response and the rest were null responders. Only two patients had $\mathrm{HBs} \mathrm{Ag}$ positive and $35 \%$ had an AIDS defining disease. The mean stiffness at the beginning of treatment was $14.35 \mathrm{kPa}$ (SD $\pm 12.3 \mathrm{kPa})$. At the end of treatment, the mean stiffness obtained by transitional elastography was $12.5 \mathrm{kPa}(\mathrm{SD} \pm 12 \mathrm{kPa})$.

Conclusions: In our series, DAA interferon-free regimes are quite effective in HIV/HCV co-infected patients (ITT: $96 \%$ of sustained viral response (SVR); DOT: $98 \%$ of SVR), regardless of fibrosis degree, cirrhosis, opioid substitution therapy, gender, PR pre-treatment or CD4 count. Stratifying by treatment, we found a decrease in the mean values measured by elastography pre and post-treatment. New studies will be needed to determine the usefulness of transitional elastography as a tool to predict the evolution of liver disease in treated patients who achieved SVR.

\section{Introduction}

Hepatitis C Virus (HCV) infection is a ubiquitous disease with a variable prevalence according to different geographical areas, focusing in some countries on specific population groups, such as in the Mediterranean basin with people with a history of parenteral substance abuse [1]. Most infected (55-85\%) have a chronic disease over the years, many of whom develop cirrhosis and / or hepatocellular carcinoma. It is estimated that 400,000 people will die annually in connection with a terminal liver disease and there are about 71 million infected people worldwide, many of whom are unaware of their serological status [2]. This is the reason why it involves a Public Health problem of the first magnitude. Currently, the standard of care for therapy against HCV infection includes direct-acting antiviral (DAAs) interferon-free regimens [3] thereby the cure of more than $95 \%$ of treated patients is achieved and the progression of liver fibrosis can be stopped or delayed, reducing the risk of death from cirrhosis and hepatocarcinoma. This leads to greater survival in patients without liver cirrhosis. These treatments are also easy to perform, totally oral, with a limited duration in time, they are generally very well tolerated and mainly with "pangenotypic activity". However, accessibility to these treatments and even the diagnosis of chronic infection is complicated and limited, especially in developing countries. In this regard, the World Health Organization (WHO) has prepared the document: "Global strategy of the health sector against viral hepatitis, 2016-2021" to plan a horizon towards the elimination of viral hepatitis, including HCV [4]. In recent years, liver stiffness measured by transition elastography, a noninvasive technique, has become the election procedure to determine the degree of fibrosis in patients with chronic HCV infection [5] and sometimes to plan the duration of treatment. It remains to be determined as a tool to predict the evolution of liver disease in treated

*Correspondence to: Ferra Murcia Sergio, Infectious Diseases Unit, Torrecárdenas University Hospital, Almería, Andalusia, Spain, E-mail: sergio. ferra.sspa@juntadeandalucia.es

Collado Romacho Antonio, Unidad Enfermedades Infecciosas, Hospital Universitario Torrecárdenas, C/Hermandad de Donantes, Almería, Andalucía, Spain, E-mail : antonior.collado.sspa@juntadeandalucia.es

Received: August 20, 2019; Accepted: August 30, 2019; Published: September 02,2019 
patients and who achieved SVR [6]. The cure of the infection or SVR is defined as the negativization of viremia at week 12 after treatment. This SVR is associated with a normalization of liver function tests and an improvement or disappearance of necroinflammation and liver fibrosis in patients without cirrhosis. In patients with cirrhosis, healing is associated with a decrease, but not elimination, of the risk of clinical events related to chronic liver disease [7].

\section{Material and methods}

Retrospective descriptive study. Review of the clinical history of the first 100 treatments with DAAs Interferon-free regimens in HIV/ HCV co-infected patients treated in our centre. Statistical analysis of variables such gender, age, risk factors, HCV-genotype, transitional elastography value and CD4 counts was performed using the SPSS statistical software package release 22.0 (IBM, Chicago, IL, USA).

\section{Results}

A total of 100 different treatments corresponding to $98 \mathrm{HIV} /$ HCV co-infected patients on follow-up at a tertiary reference hospital in Almería (Andalusia, Southern Spain) who received DAAs therapy were included in the analysis. Seventy-three (73\%) were male. Fortysix (46.9\%) had been previously treated with pegylated interferon and ribavirin (PR), of which only $11 \%$ had had a partial response and the rest were null responders. Seventy percent (70\%) were HCV genotype GT-1 (1a: 27\%, 1b: 10\%, 1 without subtype: $33 \%$ ) GT-3 14\% and genotype GT-4 16\%. Fourteen (14\%) used opioid substitution therapy (mainly methadone). Only 2 patients had HBsAg positive and $35 \%$ had an AIDS defining disease. The mean CD4 count at the start of treatment was $550 / \mathrm{mm}^{3}$ [typical deviation (SD) of $312.8 / \mathrm{mm}^{3}$ ], after 12 weeks of SVR at $602 / \mathrm{mm} 3\left(\mathrm{SD}\right.$ of $\left.312.6 / \mathrm{mm}^{3}\right)$. Baseline median of $507 /$ mm3 (after 12 weeks: 535/ $\mathrm{mm}^{3}$ ).

All patients underwent pre-treatment transitional elastography concluding that $17.5 \%$ had a grade of fibrosis F0-F1 $(<6 \mathrm{kPa}), 29.9 \%$ F2 (6.1-9.4 kPa), 29.9\% F3 (9.5-14.5 kPa) and 22.7\% F4 ( $\geq 14.6 \mathrm{kPa})$. The mean stiffness at the beginning of treatment was $14.35 \mathrm{kPa}$ (SD $\pm 12.3 \mathrm{kPa}$ ). At the end of treatment, the mean stiffness obtained by transitional elastography was $12.5 \mathrm{kPa}(\mathrm{SD} \pm 12 \mathrm{kPa})$. Forty-two (42\%) were underwent treatments that included RBV.

If we stratify for the different treatments, we found that the mean value pre-treatment measured by elastography in those patients who received a regimen based on Sofosbuvir / Daclatasvir \pm Ribavirin $(\mathrm{SOF} / \mathrm{DCV} \pm \mathrm{RBV})$ was $12.55 \mathrm{kPa}(\mathrm{SD} \pm 8.04 \mathrm{kPa})$. At the end of the treatment, an average value of $8.6 \mathrm{kPa}$ (DS $\pm 4.6 \mathrm{kPa}$ ) was obtained in this group, mostly HIV / HCV GT-3a coinfected patients. On the other hand, in the group that received treatment with Sofosbuvir / Simeprevir \pm Ribavirin (SOF / SMV \pm RBV), mainly with HIV / HCV GT-1, an average reference value of $19.64 \mathrm{kPa}(\mathrm{SD} \pm 14.6 \mathrm{kPa})$ was obtained and after finishing the treatment, a decrease of the average value to $14.7 \mathrm{kPa}(\mathrm{SD} \pm 13.5 \mathrm{kPa})$. The group that received treatment with paritaprevir / ombitasvir / dasabuvir \pm ribavirin $(3 \mathrm{D} \pm \mathrm{RBV})$, the mean value at baseline measured by elastography was $14.19 \mathrm{kPa}(\mathrm{SD} \pm$ $13.4 \mathrm{kPa})$ and post - treatment: $12.1 \mathrm{kPa}(\mathrm{SD} \pm 10.6 \mathrm{kPa})$. In this group, most of the coinfected patients were in the GT-1a. When analysing the group treated with paritaprevir / ombitasvir $(2 \mathrm{D} \pm \mathrm{RBV})$ we found an average reference value of $16.08 \mathrm{kPa}(\mathrm{SD} \pm 15 \mathrm{kPa})$ and after finishing the treatment of $8.4 \mathrm{kPa}(\mathrm{SD} \pm 5,9 \mathrm{kPa})$. All presented GT-4. It is worth noting one of the patients in this group, with a baseline value of 42.3 $\mathrm{kPa}$, which has a value of $17.3 \mathrm{kPa}$ at the end of treatment. As for the group treated with sofosbuvir / ledipasvir \pm ribavirin (SOF / LEDV $\pm \mathrm{RBV}$ ), they presented an average transitional elastography value of $11.01 \mathrm{kPa}(\mathrm{SD} \pm 10 \mathrm{kPa})$ and post-treatment: $14.9 \mathrm{kPa}(\mathrm{SD} \pm 12.2$
$\mathrm{kPa}$ ). In this group, 3 patients with hepatic decompensation prior to treatment (hepatic encephalopathy) should be noted. Mostly GT-1 and GT-4. Patients treated with grazoprevir / elbasvir (GZP / ELB) had a mean baseline pre-treatment of $9.2 \mathrm{kPa}(\mathrm{SD} \pm 1.9 \mathrm{kPa})$ and posttreatment of $8.7 \mathrm{kPa}(\mathrm{SD} \pm 0 \mathrm{kPa})$. Mostly GT-1a. Finally, comment on 2 patients treated with other treatment regimens: one of them with sofosbuvir / velpatasvir (GT-3a) with a baseline value measured by elastography of $6.9 \mathrm{kPa}$ and post-treatment of $7.7 \mathrm{kPa}$. The other patient (GT-1a not responding to previous Interferon-based therapy) received treatment with simeprevir / daclatasvir with a baseline elastography value of $2.3 \mathrm{kPa}$ and post-treatment of $4.5 \mathrm{kPa}$. Analysing both patients, we observed that the first of them, treated with SOF + VEL had a nonalcoholic steatohepatitis in the last abdominal ultrasound performed after HCV treatment with normal lipid profile, so the worsening in the values measured by transitional elastography could be related to nonalcoholic steatohepatitis. As for the other patient (treated with SMV + DCV), she had relapsed to alcohol consumption, currently under treatment with antipsychotics and poor lipid control.

The most used combination was sofosbuvir/ledipasvir (SOF/LDV) $\pm \mathrm{RBV}$ by $34 \%$, followed by $3 \mathrm{D} \pm \mathrm{RBV}$ in $25 \%$ of cases. Of the series, $95.7 \%$ had successfully completed the treatment, with 2 premature discontinuations [none of them about adverse events (AE); one reached SVR]. One patient died due to no hepatic causes. Sixty-eight (68\%) were undetectable at week 4 of treatment, $97.8 \%$ at week 8 of treatment and $98.9 \%$ at end of treatment. On intention to treat analysis (ITT) the rate of SVR was $96 \%$ [ $98 \%$ on directly observed therapy (DOT)]. Only 2 patients had a relapse (2\%; a non-cirrhotic GT-1a patient treated with sofosbuvir + daclatasvir $\times 12 \mathrm{w}$ and a non-cirrhotic GT-3a patient treated with sofosbuvir + daclatasvir $\times 12 \mathrm{w}$ ) and none had virological failure during treatment. No patient had any severe adverse event (SAE) and none had stopped therapy from any AE.

\section{Conclusions}

In our series, DAAs interferon-free regimes are quite effective in HIV/HCV co-infected patients (ITT: $96 \%$ of SVR; DOT: $98 \%$ of SVR), regardless of fibrosis degree, cirrhosis, opioid substitution therapy, gender, PR pre-treatment or CD4 count. Both relapsed patients were initially treated with the same AAD interferon-free regimen but achieved SVR after being re-treated. No SAE was observed, and no premature discontinuation was observed because any kind of $\mathrm{AE}$. Stratifying by treatment, we found a decrease in the mean values measured by elastography pre and post-treatment. New studies will be needed to determine the usefulness of transitional elastography as a tool to predict the evolution of liver disease in co-infected HIV/HCV patients treated with DAAs who achieved SVR.

\section{References}

1. Macías J, Morano LE, Téllez F, Granados R, Rivero-Juárez A et al. (2019) Response to direct-acting antiviral therapy among ongoing drug users and people receiving opioid substitution therapy. J Hepatol 71: 45-51. [Crossref]

2. European Union HCV Collaborators (2017) Hepatitis C Virus Prevalence and Level of Intervention Required to Achievethe WHO Targets for Elimination in the European Union by 2030: a Modelling Study. Lancet Gastroenterol Hepatol 2: 161-176. [Crossref]

3. EASL Recomendations on Treatment of Hepatitis C (2018) European Association for the Study of the Liver. Electronic adress: easloffice.eu; European Association for the Study of the Liver. J Hepatol S0168-8278: 31968-31978.

4. World Health Organization (2019) Global Health Sector Strategy on Viral Hepatitis 2016-2021. Towards Ending Viral Hepatitis. 2016. Available at: https://apps.who.int/ iris/bitstream/handle/10665/246177/WHO-HIV-2016.06-eng.pdf?sequence=1

5. Neukam K, Morano-Amado LE, Rivero-Juárez A, Macías J, Granados R, et al. (2017) Liver stiffness predicts the response to direct-acting antiviral-based therapy against chronic hepatitis C in cirrhotic patients. Eur J Clin Microbiol Infect Dis 36: 853-861. [Crossref] 
6. Chen SH, Lai HC, Chiang IP, SU WP, Lin CH, et al. (2018) Changes in Liver Stiffness Measurement Using Acoustic Radiation Force Impulse Elastography after Antiviral Therapy in Patients with Chronic Hepatitis C. PloS ONE 13: e0190455. [Crossref]
7. Spanish association for the study of the liver (AEEH) - Spanish Society Infectiology and Clinical Microbiology (SEIMC). AEEH-SEIMC guide to treatment of Hepatitis C virus infection 2018. Available at: https://seimc.org/contenidos/gruposdeestudio/ gehep/dcientificos/documentos/gehep-seimc_AEEH-dc-2018-HepatitisC.pdf

Copyright: (C2019 Murcia FS. This is an open-access article distributed under the terms of the Creative Commons Attribution License, which permits unrestricted use, distribution, and reproduction in any medium, provided the original author and source are credited. 